\title{
Editorial: Academics, programmes, and methodologies for fostering students' competences
}

\author{
Luigi F. Donà dalle Rose \\ Editor
}

Anna Serbati

Assistant Editor

doi: http://dx.doi.org/10.18543/tjhe-6(1)-2018pp13-17

As you may remember from our first Editorial (Volume 3, issue No. 1, November 2015), one of our aims was to put "a continuing effort" in order to include our Journal in international abstract and citation databases of peer-reviewed literature. Accordingly, the Editorial Team which includes Editor, Assistant Editor and Managing Editor (Dr. Ladislas Bizimana Kayinamura), applied for inclusion in SCOPUS and in WoS-Web of Science. We are now happy to announce that, after a process involving nearly two years, our Journal has been accepted for inclusion in SCOPUS on September $9^{\text {th }}, 2018$. The evaluation of the second application is still in progress.

On this occasion, we warmly thank the Editorial Board for continuous and concrete support. We gratefully acknowledge the merits of our contributors, reviewers and readers, who in these recent years enhanced the quality of our Journal. The greatest credit must go to all of them and we are also fully aware that the future of the Journal lies in their hands. Please continue to contribute, circulate, cite, comment, and debate! We invite, again on behalf of the Editorial Board, submissions from "all those working to improve the quality, transparency, transferability and relevance of higher education programmes and who wish to share their experience with the global community via the pages of this journal."

We remind that in these years the list of contribution topics has been detailed to better cover the many topics in the field of higher education and to attract actors (see http://www.tuningjournal.org/about/editorialPolicies\# custom-3).

1 Paul Ryan, “Editorial,” Tuning Journal for Higher Education 1, no. 1 (2013): 13. 
In the letter from SCOPUS it was written, among several other things: "the Editorial teams are to be commended for developing the journal across teaching and learning internationally". If we include the present Issue, our Journal has covered almost all continents (Oceania is still missing) with nearly 30 regional articles and 32 country-related articles, out of a total of 69 articles. Moreover, the present Issue hosts for the first time contributions from two BRICS countries, i.e. China and South Africa.

The title of the present Issue is Academics, programmes, and methodologies for fostering students' competences. The focus is again "fostering students' competences", but - given the complexity of higher education systems - "fostering" may best occur if the several involved actors are accordingly prepared and if the many intermediate steps are properly taken care of. In other terms, as we all know, the winds of innovation may follow quite different paths for new implementations and actual improvements, according to local situations, country- and time- priorities and according to the good will of actors.

Indeed, the present Issue starts with the assessment made among some U.S. history academics on the impact of the paradigm shift in teaching and learning brought about by the Tuning and other projects. Next, a quite comprehensive overview of the innovative changes occurring in the field Engineering Education in China in recent years is presented (a most important step at discipline and programme level). The following article deals with the challenge of measuring with a compact operational tool the quality of a degree programme and at the same time the quality of its component units (an innovative step for programme planners and evaluators, carried out in Japan). Then, an experience aimed at re-designing a fourth year of the Bachelor of Education in a South African university on the basis of a constructive alignment methodology is described (again a step at programme planners level).

The conclusive article in this issue is quite different from the others and deals with the possible global role to be played by universities as institutions for research, education and any other third mission, in our quickly changing world. We hope that the fundamentals extensively described in this paper may start a fruitful debate among readers and potential future authors.

The first article of the present Issue, by Daniel McInerney, describes a rather unique approach to the Tuning methodology developed by the American Historian Association (AHA), which led an "AHA Tuning" project, involving its members and starting in 2012. After six years of work, the author explores with the help of an exhaustive questionnaire "the practical application and implementation of Tuning discussions, the ways in 
which broad frameworks and desired proficiencies are realized through concrete, tangible changes in classroom teaching, assignments, assessments, and outreach. This record of on-the-ground praxis rests at the heart of the survey". The article offers an introduction with an updated bibliography about History "Tuners". It gives interesting and abundant data about how U.S. historians (about 300 respondents) perceived the innovative methodology and its concrete fruits, in short "about how Tuning operates "on the ground".

The second contribution flies at a different height, from the micro-level "on the ground" of the previous article to the macro-level of international agreements which favour profound innovative process at national level. The article by Tengteng Zhuang and Xiaoshu Xu describes the ambitious process named "New Engineering Education (NEE)", started by China after joining the Washington Accord ${ }^{3}$ in 2016 and in the wake of the "broader global technological revolution" (e.g. the concept of 'Industry 4.0'). The article describes in detail the three founding policy documents issued by China's Ministry of Education in 2017, namely 'Fudan Consensus', 'Tianda Action', and 'Beijing Compass'. In order to understand here the flavor of the process, the "Tianda Action" underlines the need to "build up a student-centered concept, enhance faculty-student interaction, reform teaching methods and assessment methods in order to form a learner centered engineering education pattern'. Moreover, according to the authors, "NEE puts a prominence on promoting connectedness among different disciplines as an approach to educating prospective engineers at higher education institutions". References to other ongoing and similar processes in the world are made whenever appropriate. The article also describes the concrete actions, taken to enforce NEE and now in progress, and the possible challenges and limits of such a huge upgrading process.

The following article by Kayo Matsushita, Kazuhiro Ono, and Yugo Saito deals with the assessment of learning outcomes in the context of the "current assessment research regarding how to connect the course- and program-level assessments". This is one of most important aspects in the present/advanced QA procedures.

The authors - on the basis of a consolidated experience for assessing performances in Problem Based Learning courses in the programme for Dental Education at the Faculty of Dentistry at Niigata University - propose

\footnotetext{
2 Daniel McInerney, e-mail to the Editors, 9 May 2018.

3 The Washington Accord can be presented as "an international agreement between bodies responsible for accrediting engineering degree programmes," http://www.ieagreements. org/accords/washington/.
} 
a "modified" Triple Jump assessment at the level of key courses of the whole programme. Then they insert/embed these by now "double duty" assessments in an innovative method to integrating course-level and program-level assessments. The proposed method is named "Pivotal Embedded Performance Assessment", PEPA for short. According to the authors, the method could be profitably used also in medical and pharmaceutical education and possibly in other fields (e.g. educational programmes for teachers and legal professions). Indeed, they hope to explore a possible PEPA's extension to other fields in their future research work.

The article by Melanie Bernadette Luckay deals with the redesign of the last year of a 4-years Bachelor in Education at University of the Western Cape (UWC) and focuses on the course "Educational Practice", which covers $25 \%$ of the whole programme (in terms of local credits) and which progressively develops along the four Bachelor years. The author uses here, as a framework for re-designing the course, the basic concepts of Biggs' Constructive Alignment. In this way, the author is able to integrate the different levels of competences, which are simultaneously required by the new (2015) national policy document Minimum Requirements for Teacher Education Qualification (MRTEQ), by the university itself (i.e. the so-called graduate attributes) and by the programme requirements (i.e. the Intended Learning Outcomes), with a careful eye on the corresponding appropriate assessment tools. The article highlights the many challenges of the process, particularly in order to take care of the unequal preparation of students who enter the first Bachelor year. As a whole, the article wants to be, in the words of this passionate author, "a discussion on the journey that the Faculty staff embarked on towards changing and adapting the Bachelor of Education programme".

The last article in this Issue puts an important question and - we hope gives the basic inputs for a further future debate. Francisco Del Canto Viterale wants "to analyze the role of the university within the changing world order of the $21^{\text {st }}$ Century". Within this broad scope, he carries out an extensive review of the existing literature in the fields of International Studies, Education Sciences, and other Social Sciences. After a synthetic description of the main "characteristics" shown by universities in the past centuries, the author offers an analysis of the new international context which is going through a stage of intersystem transition - in terms of actors, relationships, new relevant topics, and processes (as many as six main processes are identified). In this varied context, the author presents the main challenges which the university is facing, some of them seemingly important for, and linked to, the future of the planet. Finally, the author outlines 
possible strategies for reconfiguration and adaptation processes of the university, in some cases already in place, which might help the university itself to understand extent and limits of its role as a "global actor". We renovate here the wish that this paper may start a fruitful debate among readers and potential future authors. 


\title{
Editorial: Academics, programmes, and methodologies for fostering students' competences
}

\author{
Luigi F. Donà dalle Rose \\ Editor
}

Anna Serbati

Assistant Editor

doi: http://dx.doi.org/10.18543/tjhe-6(1)-2018pp13-17

\section{Copyright}

Copyright for this article is retained by the Publisher. It is an Open Access material that is free for full online access, download, storage, distribution, and or reuse in any medium only for noncommercial purposes and in compliance with any applicable copyright legislation, without prior permission from the Publisher or the author(s). In any case, proper acknowledgement of the original publication source must be made and any changes to the original work must be indicated clearly and in a manner that does not suggest the author's and or Publisher's endorsement whatsoever. Any other use of its content in any medium or format, now known or developed in the future, requires prior written permission of the copyright holder. 